\title{
THE EFFECTS OF DEXTRAN IN NORMOVOLEMIC AND OLIGEMIC SUBJECTS ${ }^{1}$
}

\author{
BY JAMES F. HAMMARSTEN, BEN I. HELLER, AND RICHARD V. EBERT
}

\author{
(From the Veterans Administration Hospital and the Department of Medicine, The Medical \\ School, University of Minnesota, Minneapolis, Minn.)
}

(Submitted for publication November 10, 1952 ; accepted December 31, 1952)

Dextran, a macromolecular plasma volume expander, was first used in 1943. Since that time, many clinical reports have appeared in the Scandinavian and English literature. In 1942 the Blood Substitute Committee of the National Research Council listed 11 requirements for a satisfactory plasma volume extender. These are: maintenance of satisfactory colloid osmotic pressure, constant composition, suitable viscosity, stability with temperature change, stability in storage, ease of sterilization, freedom from pyrogens, absence of immediate adverse effects, absence of immediate or delayed organic derangement, absence of antigenicity, and reasonable price (1). Dextran seems to fulfill all of these requirements except for the possible possession of antigenic properties. In addition, it has been suggested that a satisfactory extender should remain in the circulatory system, maintain increased plasma volume, and keep blood circulatory levels up to 50 per cent of the amount infused for at least 12 hours (1). Although it is of paramount importance that effects of any plasma volume expander upon plasma volume and plasma protein restitution be investigated, there has been a paucity of such reports in the literature.

\section{METHODS}

The experimental procedure was divided into two parts. In the first part, after control studies were performed, one liter of 6 per cent dextran ${ }^{2}$ in saline was administered

1 Sponsored by the Veterans Administration and published with the approval of the Chief Medical Director. The statements and conclusions published by the authors are the result of their own study and do not necessarily reflect the opinion or policy of the Veterans Administration.

2 Clinical dextran, lot No. 84667A, Commercial Solvents Corporation, was administered to six patients. Four patients received clinical dextran prepared at the Northern Regional Research Laboratory, Peoria, Illinois from Strain NRRL-B-742. Since the effects of these two forms of dextran did not differ significantly, they have been considered collectively in the tabulation of results.

All of the subjects who were bled received clinical dex- intravenously in 50 minutes to 10 male patients convalescent from various diseases. The patients had no evidence of cardiovascular or renal disease and varied in age from 19 to 37 years. The plasma volume was measured one and six hours after the administration of dextran. The hematocrit, plasma protein concentration, plasma dextran concentration, and urinary dextran excretion were measured at 1,6 , and 24 hours.

The second part of the experiment consisted of the investigation of the effects of dextran after hemorrhage. The subjects were eight healthy male physicians varying in age from 25 to 32 years. After the control studies were performed, one liter of blood was removed from the antecubital vein in 15 minutes. Immediately thereafter, one liter of 6 per cent dextran in saline was administered intravenously during a 40 minute period. The plasma volume was measured at 6 and 24 hours in all subjects, at 1 hour in five subjects and at 12 hours in three subjects. The hematocrit, plasma protein concentration and plasma dextran concentration were determined at $1,6,24$, and 48 hours in all subjects and at 12 hours in three subjects. The urinary dextran excretion was determined at 1,6 , and 24 hours in all subjects and at 12 hours in three subjects.

The plasma volume was measured by the $\mathrm{T}-1824$ dye method as previously reported (2). Samples were drawn at five minute intervals from 10 to 35 minutes after dye administration. The red cell volume was calculated from the total blood volume and plasma volume. The total blood volume was calculated from the plasma volume and the hematocrit which was corrected for 4 per cent trapped plasma. Plasma protein concentration in the subjects who were bled was determined by the microKjeldahl method. In the other group plasma protein concentration was determined by the tyrosine method (3) and frequently checked by the micro-Kjeldahl method. Protein could not be determined by the biuret method since dextran is precipitated by copper in an alkaline medium. Dextran was determined by the method of Bloom and Wilcox (4).

\section{RESULTS}

The administration of dextran produced a very slight elevation of blood pressure in most subjects. There were no changes in pulse or temper-

tran, lot No. 84667A, Commercial Solvents Corporation. 
TABLE I

Effects of administration of 1 liter of dextran *

\begin{tabular}{|c|c|c|c|}
\hline & 1 & Time in hours & 24 \\
\hline $\begin{array}{l}\text { Increase in plasma volume (ml.) } \\
\text { Decrease in hematocrit (\%) } \\
\text { Change in red cell volume (ml.) } \\
\text { Decrease in plasma proteir concentration (\%) } \\
\text { Change in total circulating protein (grams) } \\
\text { Plasma dextran concentration (mg. per } 100 \mathrm{ml} \text {.) } \\
\text { Total circulating dextran (grams) } \\
\text { Cumulative urinary dextran excretion (grams) } \\
\text { Dextran unaccounted for (grams) }\end{array}$ & $\begin{array}{r}775 \pm 150 \\
12.4 \pm 2.1 \\
-9 \pm 168 \\
21.7 \pm 2.5 \\
-2.1 \pm 10.6 \\
1,072 \pm \\
39.4 \pm 2.5 \\
13.6 \pm 2.5 \\
7.0 \pm \quad 3.9\end{array}$ & $\begin{array}{l}534 \pm 117 \\
8.6 \pm 2.1 \\
33 \pm 132 \\
12.7 \pm 2.7 \\
6.9 \pm 13.6 \\
684 \pm 75 \\
23.4 \pm 1.7 \\
22.5 \pm 4.3 \\
15.1 \pm 4.9\end{array}$ & $\begin{aligned} 5.3 & \pm 2.6 \\
5.3 & \pm 4.7 \\
416 & \pm 36 \\
28.6 & \pm 6.0\end{aligned}$ \\
\hline
\end{tabular}

* All values are expressed as the mean and standard"deviation.

ature. The removal of one liter of blood was not associated with any change in pulse and was associated with symptoms in only one subject. This subject developed transient faintness, nausea, and tingling in the hands and feet. Following the completion of the experiment, one subject developed headache, fever, anorexia, diarrhea, and splenomegaly. The illness was of 10 days' duration. Extensive clinical and laboratory investigation failed to reveal a specific diagnosis.

The effects of the administration of one liter of dextran to patients with a normal blood volume are given in Table I. The plasma volume increased $775 \mathrm{ml}$. at one hour. At six hours the increase was $534 \mathrm{ml}$. There was a corresponding decrease in plasma dextran concentration from 1,072 to 684 mg. per $100 \mathrm{ml}$. during this time. The urinary dextran excretion was 22.6 per cent of the injected dose ( 60 grams) in one hour. An additional 15 per cent was excreted from one to six hours.
There was no statistically significant change in the total circulating proteins and the red cell volume. From the increase in plasma volume and from the values for total circulating dextran it was calculated that there was a retention of $21.2 \mathrm{ml}$. of water per gram of dextran.

The effects of the administration of one liter of dextran following the removal of one liter of blood are given in Table II. The increases in plasma volume were determined using the plasma volume immediately after venesection as the baseline. The plasma volume immediately after venesection was calculated by subtracting the amount of plasma removed from the control plasma volume. The changes in plasma volume thereafter are illustrated graphically in Figure 1. There was an increase in plasma volume of approximately one liter in one hour. The plasma dextran concentration was $1,160 \mathrm{mg}$. per $100 \mathrm{ml}$. in one hour and fell progressively to $247 \mathrm{mg}$. per $100 \mathrm{ml}$. in 48 hours.

TABLE II

Effects of administration of 1 liter of dextran following removal of 1 liter of blood *

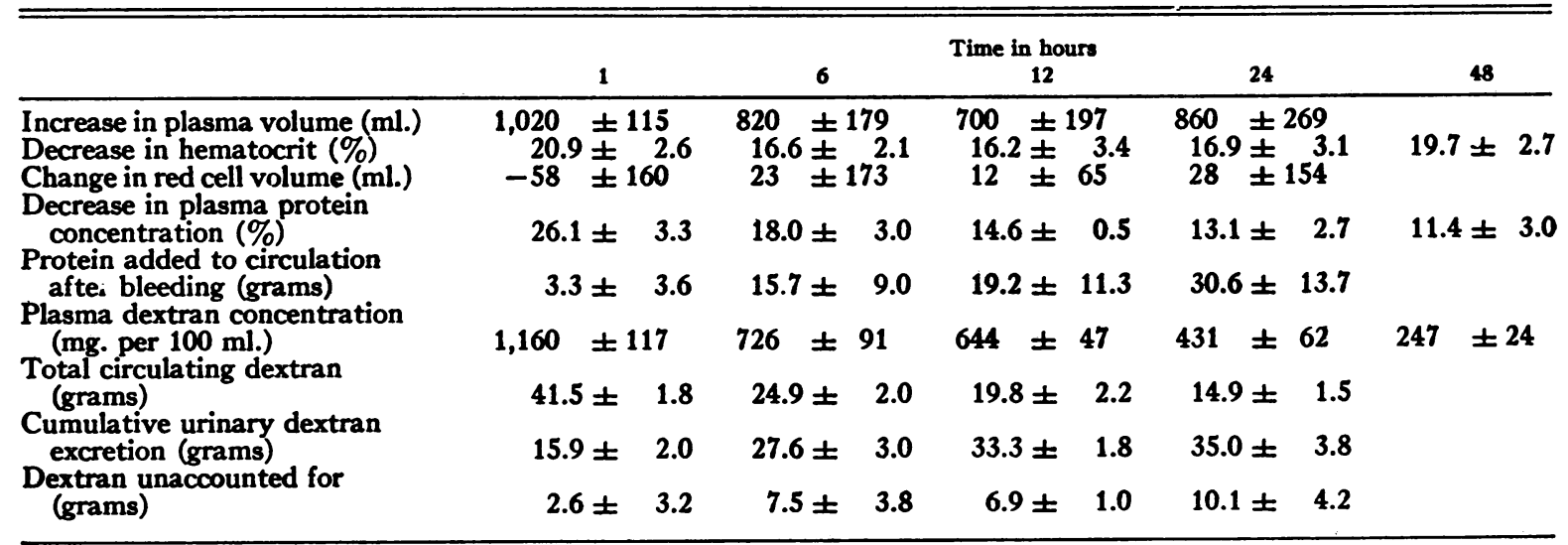

* All values are expressed as the mean and standard deviation. 


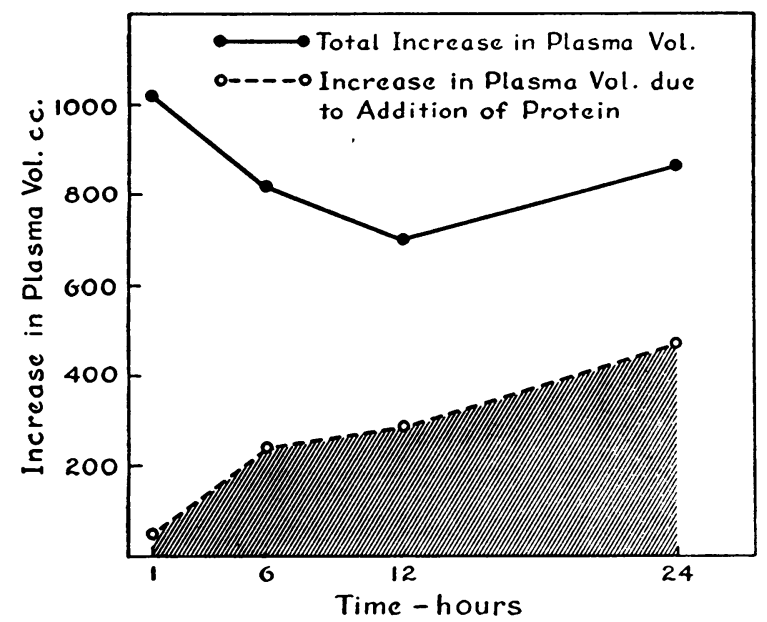

Fig. 1. Increase in Plasma Volume following Dextran Administration to Oligemic Subjects

The shaded area represents the increase in plasma due to the addition of protein to the circulation.

The urinary dextran excretion in one hour was 26.4 per cent of the injected amount. An additional 19.4 per cent was excreted from one to six hours and 12.4 per cent in 6 to 24 hours. The amount of dextran that could not be accounted for in the plasma and urine increased from 2.6 grams in one hour to 10.1 grams at 24 hours. This is noted graphically in Figure 2. The addition of plasma protein to the circulation increased from 3.3 grams during the first hour after the dextran infusion to 30.6 grams at 24 hours. There was no significant change in red cell volume during the time of the experiment.

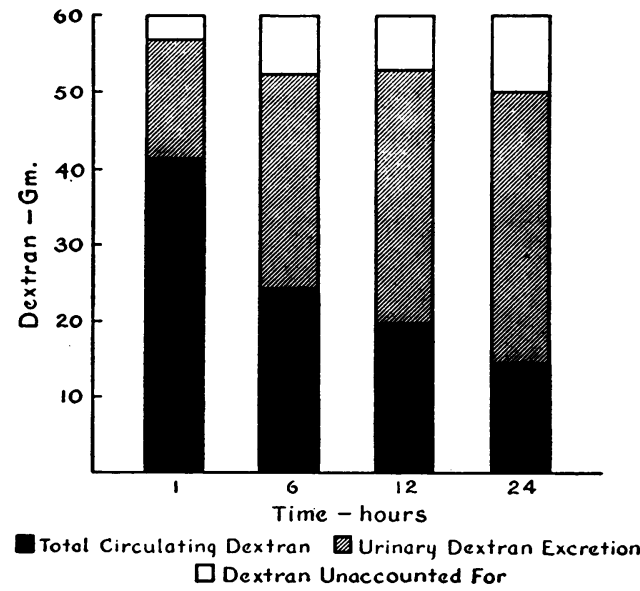

Fig. 2. Total Circulating Dextran, Urinary Dextran Excretion, aNd Dextran Unaccounted for in Subjects Who Were Bled

\section{DISCUSSION}

From the results presented it is apparent that dextran is effective in increasing plasma volume in both the normovolemic subjects and in subjects who were bled. The plasma dextran concentration and the urinary excretion of dextran were similar in the two groups. The important question has been raised as to whether the normovolemic or the hypovolemic patient or animal should be used for the evaluation of plasma expanders (5). Some investigators believe that homeostatic mechanisms may correct a supernormal volume rapidly and that more of the infused material will be excreted in the urine $(5,6)$. This was not borne out in our experiments. It is not intended to imply, however, that the renal excretion of dextran would be similar in subjects with greater blood loss.

During the various experimental periods, some of the administered dextran was unaccounted for by addition of the total circulating dextran and urinary dextran excretion (Figure 2). This experiment provides no specific information as to the fate of this portion. It is assumed that a considerable fraction of the dextran which is unaccounted for is present extravascularly during the early part of the experiment and that some may be metabolized. It has been previously demonstrated that dextran appears rapidly in lymph (7). Experiments utilizing $\mathrm{C}^{14}$ tagged dextran showed that over 90 per cent of a dose of dextran was eliminated in 10 days. Sixty-four per cent appeared in the urine and 26 per cent in the expired air as carbon dioxide (8). The excretion of dextran as carbon dioxide began almost immediately and reached a peak on the second to third day. There is also evidence that dextran is metabolized to glucose (9).

Following hemorrhage the administration of dextran was associated with an increase in plasma volume, which was sustained for 24 hours. The increase at 24 hours was $860 \mathrm{ml}$. This is in contrast to the normovolemic subjects in whom the increase in plasma volume was only $534 \mathrm{ml}$. at six hours. A further decrease in plasma volume of this group occurred at 24 hours as evidenced by the hematocrit. The difference between the two groups is not related to the amount of circulating dextran but rather to the addition of significant amounts of protein to the circulation in the bled 
subjects. Hemodilution due to such addition of protein becomes progressively more important as is graphically illustrated by the shaded area in Figure 1. At 1, 6, and 24 hours there were 3.3, 15.7 , and 30.6 grams of plasma protein, respectively, added to the circulation of subjects who were bled. This is comparable to the values reported by Ebert, Stead, and Gibson (10) in a bleeding experiment in which no plasma volume expander was administered. It is therefore apparent that dextran has no inhibitory effect on the innate ability of an oligemic subject to add protein to the circulation and to restore the blood volume to normal.

It has been suggested by Rosenqvist and Thorsen (11) that dextran lowers the concentration of plasma proteins by dilution and also by supplanting plasma proteins, particularly albumin. If it were true that dextran inhibited the addition of protein to the circulation, then the plasma volume in the oligemic subjects would have declined rapidly. The rapid urinary excretion of dextran, unassociated with the natural process of hemodilution, would not have permitted a sustained increase in plasma volume. Our studies do not confirm the observations of Rosenqvist and Thorsen.

Kinard and Bloom (6) and Bohmansson and his coworkers (12) have suggested that the administration of dextran will cause the addition of red blood cells to the active circulation. Our data indicate that there was no appreciable early addition of red cells to the circulation in response to dextran nor in response to hemorrhage followed by the administration of dextran. The greater decrease in protein concentration as compared to the hematocrit is to be expected since the per cent increase in plasma volume is greater than the per cent increase in the total blood volume. The apparent discrepancy in change of the protein concentration and the hematocrit should not be construed as indicating the addition of red cells to the circulation.

The total circulating dextran at 12 hours was 33 per cent of the amount injected. This does not satisfy the proposed requirement that the circulatory level should be maintained at 50 per cent for 12 hours (1). It is noteworthy, however, that despite the decrease in plasma dextran concentration, the plasma volume remained relatively stable. Dextran has a colloid osmotic pressure approximately that of plasma. Hence, a better criterion for adequate retention of dextran in the plasma would be a degree of retention sufficient to insure that the sum of the circulating dextran and the protein added to the circulation remains relatively constant at a value sufficient to sustain a satisfactory increase in plasma volume. In these experiments this sum was $45,41,39$, and 46 grams at 1, 6, 12 and 24 hours, respectively. Bull and associates (13) have indicated this in another manner by stating that "the main function of the substitute would clearly be to restore circulating blood volume until the patient's own plasma protein returned to the circulation." Since dextran fulfills this criterion, it must be considered as a satisfactory plasma volume expander.

\section{SUMMARY}

Dextran was administered to subjects with a normal blood volume and to subjects with oligemia induced by the rapid removal of one liter of blood. The effect of dextran in expanding the plasma volume was more prolonged in those subjects who were bled. This is accounted for by the addition of plasma protein to the circulation. The importance of the restitution of plasma proteins in the evaluation of any plasma volume expander is discussed.

\section{REFERENCES}

1. Report of Working Conference on Dextran, National Research Council, Subcommittee on Shock and Northern Regional Research Laboratory, Oct. 29, 1951.

2. Schultz, A. L., Hammarsten, J. F., Heller, B. I., and Ebert, R. V., A critical comparison of the T-1824 dye and iodinated albumin methods for plasma volume measurement. J. Clin. Invest., 1953, 32, 107.

3. Greenberg, D. M., The colorimetric determination of the serum proteins. J. Biol. Chem., 1929, 82, 545.

4. Bloom, W. L., and Wilcox, M. L., Determination of dextran in blood and urine. Proc. Soc. Exper. Biol. \& Med., 1951, 76, 3.

5. Ravdin, I. S., Plasma expanders. J. A. M. A., 1952, 150, 10.

6. Kinard, C., and Bloom, W. L., The prolonged effect of dextran on plasma volume expansion. Progress Report National Research Council, Subcommittee on Shock, May 12, 1952.

7. Grotte, G., Knutson, R. C., and Bollman, J. L., The diffusion of dextrans of different molecular sizes to lymph and urine. J. Lab. \& Clin. Med., 1951, 38, 577. 
8. Hellman, L., National Research Council Report, Oct., 1951.

9. Gray, I., Siiteri, P. K., and Pulaski, E. J., Metabolism of plasma substitute. I. Dextran (Macrodex). Proc. Soc. Exper. Biol. \& Med., 1951, 77, 626.

10. Ebert, R. V., Stead, E. A., Jr., and Gibson, J. G., II, Response of normal subjects to acute blood loss, with special reference to the mechanism of restoration of blood volume. Arch. Int. Med., 1941, 68, 578.
11. Rosenquist, H., and Thorsén, H. G. R., Macrodex in the treatment of extensive burns. Arch. Surg., 1951, 62, 524.

12. Bohmansson, G., Rosenqvist, H., Thorsén, G., and Wilander, O., Clinical experiences with dextran as a plasma substitute. Acta. chir. Scandinav., 1946, 94, 149.

13. Bull, J. P., Ricketts, C., Squire, J. R., Maycock, W. d'A., Spooner, S. J. L., Mollison, P. L., and Paterson, J. C. S., Dextran as a plasma substitute. Lancet, 1949, 1, 134. 